\title{
Predictors of self-reported physical activity level in patients with non-specific chronic low back pain
}

\begin{abstract}
Background: Physical activity (PA) and exercise is recommended in clinical guidelines for the maintenance of good health status and management of Non-specific chronic low back pain (NSCLBP). At present, no study has evaluated the predictive factors of self-reported PA level among patients with NSCLBP. This study sought to determine the predictors of self-reported PA level among patients with NSCLBP.
\end{abstract}

Methods: This cross-sectional survey involved 57 participants conveniently recruited from the physiotherapy department of a tertiary hospital. Four self-administered questionnaires: A structured socio-demographic data questionnaire, Roland Morris Disability Questionnaire (RMDQ), Modified Assessing Levels of Physical Activity (ALPHA) environmental questionnaire and long form of International Physical Activity Questionnaire (IPAQ) were used for data collection. Descriptive statistics was used to summarize data in the frequency and percentage tables. A step-wise multiple regressions were used to determine the predictors of the four domains of PA (job-related (JRPA), transport - related (TRPA), domestic/garden-related (DGPA) and leisure time-related (LTPA)). Alpha level was set at $\mathrm{p}<0.05$.

Results: Males had a higher JRPA, TRPA and LTPA. Females had a higher DGPA. The socio-demographic, clinical and environmental variables assessed in the study were only able to account for $45.9 \%, 60.6 \%, 97 \%$ and $60.7 \%$ of the variance in JRPA, TRPA, DGPA and LTPA domains respectively.

Conclusion: PA level of NSCLBP patients were moderately high and predicted by some socio-demographic, clinical and perceived environmental variables. More emphasis should be placed on the assessment of these selected variables to improve on the management of NSCLBP and thus obtain optimum outcome.

Keywords: physical activity, predictors, non-specific chronic low back pain
Volume 4 Issue I - 2019

\author{
Antoninus Obinna Ezeukwu,' Gideon \\ Chidiebere Ebisike,' Davidson Okwudili \\ John, ${ }^{2}$ Obinna Chinedu Okezue,' Jeneviv \\ Nene John' \\ 'Department of Medical Rehabilitation, Faculty of Health \\ Sciences and Technology, University of Nigeria Enugu Campus, \\ Nigeria \\ ${ }^{2}$ Department of physiotherapy, Federal Teaching Hospital, Ebonyi \\ State, Nigeria
}

Correspondence: Jeneviv Nene John, Department of Medica Rehabilitation, Faculty of Health Sciences and Technology, College of Medicine, University of Nigeria, PMB 01 I 29 Enugu State, Nigeria, Tel+2348038781954, Email cynthia.john@unn.edu.ng

Received: January 20, 2019 | Published: February 06, 2019

\section{Introduction}

Non-specific chronic low back pain (NSCLBP) is defined as chronic low back pain not attributable to a recognizable, known specific pathology (e.g., infection, tumor, osteoporosis, lumbar spine fracture, structural deformity, inflammatory disorder, radicular syndrome, or cauda equina syndrome). ${ }^{1}$ Non- specific low back pain can be classified as: acute, sub-acute and chronic low back pain. Acute low back pain is an episode of low back pain for less than 6 weeks, sub-acute: low back pain between 6 and 12 weeks and chronic low back pain for 12 weeks or more. ${ }^{2}$ NSCLBP has various impacts on body functions, activity and participation in daily life,,$^{3-5}$ and it is a common cause for attending healthcare. ${ }^{1}$ It can have serious effect on different levels - functional, psychosocial and socio-economical being of an individual. Non-specific low back pain is a common complaint in the young and is more prevalent in older adolescents and females. ${ }^{6}$ The patient with Low Back Pain (LBP) not only suffers from physical discomfort, but also from functional limitation, which might cause disability and interfere with their quality of life. ${ }^{7}$ Low back pain has been shown to have an association with physical activity at work and in leisure time, certain lifestyle factors and demographic characteristics.

According to physical activity guidelines for Americans (2008), Physical activity level is defined as any bodily movement produced by the contraction of skeletal muscle that increases energy expenditure above a basal level. ${ }^{9}$ It includes the full range of human movement and can encompass everything from competitive sport and active hobbies to walking, cycling and the general activities performed in daily living (such as house chores, working in a workshop or office). It is generally accepted that physical activity confers benefits to psychosocial health, functional ability and general quality of life, ${ }^{10,11}$ hence has been recommended over times in the control and management of chronic low back pain, ${ }^{12}$ cum mitigating against its potential risk factors. ${ }^{11}$

Different methods for evaluating physical activity are available, varying from simple patient reports to sophisticated, technically oriented ambulatory monitoring. ${ }^{13}$ Selection of an appropriate evaluation method is primarily based on the specific dimension of physical activity to be evaluated, methodological quality, and feasibility. ${ }^{14}$ Physical activity levels are sparsely measured in Low Back Pain trials. This may be because accurate assessment of activity level is not easily accomplished since instruments that provide direct measures of physical activity, such as accelerometers, pedometers or doubly labeled water technique are not readily available to the clinicians and/or are not economical and time effective for use in large groups of people. Therefore, subjective means such as self-reported instruments in the measurement of physical activity level of various strata of people in the general population has been on the increase. This may be seen as a response to the call for a cheaper yet effective means of assessing physical function.

Physical activity tends to be altered following low back pain and visa-vis a complex network of factors influencing it even in LBP varying widely in different populations. Some studies have posited that low 
levels of physical activity among chronic LBP patients are associated with certain life style factors and demographic characteristics, ${ }^{8}$ high levels of fear-avoidance beliefs and pain catastrophizing. ${ }^{15}$ While a large number of studies have focused on individual determinants (such as motivation or self-efficacy), less has been available in the physical activity literature regarding influence of the perceived physical environment (such as the presence of sidewalks, availability of recreational facilities etc) on the physical activity level of patients with non-specific chronic low back pain.

Prognostic factors for the transition from non-specific acute LBP to CLBP have previously been described in personal and socioeconomic areas as well as in all domains of the International Classification of Functioning, Disability and Health (ICF), ${ }^{16-21}$ but not in PA level point of view. Given its high rate of prevalence, investigation of the course of NSCLBP and possible predictive factors is needed for effective patient management, especially when modifiable predictive factors can be identified. However, from available literature, no information is available about the predictive factors on the level of physical activity engaged by patients with NSCLBP especially with regards to their socio-demographic, clinical and environmental characteristics. This study therefore aimed at determining the predictors of self- reported PA level among patients with NSCLBP.

\section{Methods}

\section{Research Design}

The study was a descriptive survey to evaluate the predictors of PA level among patients with NSCLBP.

\section{Subject selection}

57 patients (25 males, 32 females) were recruited for the study using a convenient sampling method based on their willingness and availability. They were recruited from the out-patient physiotherapy clinic of a tertiary hospital. The sample size was calculated with the Taro Yamane's formula;

$$
\mathrm{ss}=\mathrm{N} /\left(1+\mathrm{Ne}^{2}\right)
$$

Where ss $=$ sample size,

$\mathrm{N}=$ population size, $\mathrm{e}=$ sampling error $=0.05$. For the purpose of this study, $\mathrm{N}=61$. Therefore, $\mathrm{ss}=61 /[1+61(0.05 \times 0.05)]=52$.

Inclusion criteria were: age range of 15-69 years (IPAQ age requirement), patients diagnosed of NSCLBP who were receiving physiotherapy treatment. Exclusion criteria include: pregnant females, neurologic complications associated with lumbar disc herniation, known psychiatric illness, patients who have undergone any back surgery in the previous three months and patients with known structural back abnormality.

\section{Data collection instruments}

\section{Roland morris low back disability questionnaire (RMDQ) ${ }^{22}$}

This was used to assess disability level. It consists of 24 items. Scores on this questionnaire ranged from 0 (indicating no disability) to 24 (indicating severe disability). The reliability and validity of this questionnaire has been reported in previous studies. ${ }^{23}$

Modified assessing levels of physical activity and fitness (ALPHA) environmental questionnaire

This was used to assess the environmental perception in relation to PA. The questionnaire contains 39 items grouped in 8 themes. Each item contains question which refers to: types of residences in your neighbourhood, distances to local facilities, walking infrastructure in your neighbourhood, how pleasant is your neighbourhood, neighbourhood safety, cycling and walking network, home environment and workplace or study environment. It is valid and reliable in assessing environmental factors related to PA. ${ }^{24}$

\section{Long form of the international physical activity questionnaire} (IPAQ)

This was used to assess the patients PA level. IPAQ consists of five domains of activity namely: leisure-time physical activity (LTPA), job-related physical activity (JRPA), transport-related physical activity (TRPA), domestic and gardening physical activity (DGPA). Items in the questionnaire were structured to provide separate domain specific scores for walking, moderate-intensity and vigorous-intensity activity. The Long Form of IPAQ has been used as a standardized measure to estimate habitual practice of PA of population from different countries and sociocultural context. ${ }^{25}$

\section{Numerical rating scale}

This was used to rate the patients pain level. It has indicators from 0 to 10 categorizing pain into: no pain, mild pain, moderate pain and severe pain. This scale has an excellent reliability and validity for rating back pain. ${ }^{26}$

\section{Self-structured questionnaire}

This was used to assess the socio-demographic characteristics and clinical profile of the participants. Socio-demographic characteristics such as Age, Marital status, employment status, educational status, financial status, smoking and alcohol status. Clinical profile status such as duration of LBP, No of physiotherapy treatment sessions, Pain intensity and BMI.

\section{Height Scale (Ayron 226, USA)}

A height scale, calibrated in centimeter was used to measure the heights of the participants to the nearest $0.1 \mathrm{~cm}$.

\section{A weighing scale (Secca 287, Germany)}

This was used to obtain the weight of the participants to the nearest $0.1 \mathrm{~kg}$.

\section{Tape measure}

A non-elastic tape measure (Model: HD2020, Shanghai Kearing Stationary Co., Ltd, Shanghai, China) of range 0 - 150 centimeters was used to measure the chest, waist and hip circumference to the nearest $0.1 \mathrm{~cm}$.

An Omron (Karada Scan HBF-375) was also used to determine the percentage body fat. It has been reported to be accurate for use in the estimation of body fat. ${ }^{27}$

\section{Procedure for data collection}

\section{Ethical consideration}

An ethical approval was sought and obtained from the institutional Health Research and Ethics committee. The aim of the study and the procedures were explained to the patients who then read and signed the informed consent form.

\section{Demographic measurement}

Height of each participant was measured using a stadiometer. The participants were instructed to stand bare-footed in an upright 
position on the platform of the stadiometer. The horizontal projection of the stadiometer was placed on the vertex, crushing the hair as much as possible. The researcher checked that the feet did not come off the floor and that the position of the head was still maintained, the readings were read off to the nearest 0.1 centimeter.

To measure the weight, participants were instructed to stand barefooted on the platform of the weighing scale with feet apart and weight evenly distributed. The researcher checked that the reading of the scale was on zero. The reading was recorded to the nearest $0.1 \mathrm{~kg}$.

Body mass index (BMI) $\left(\mathrm{kg} / \mathrm{m}^{2}\right)$ was calculated by dividing the weight in kilograms $(\mathrm{kg})$ with height in square meters $\left(\mathrm{m}^{2}\right)$. Waist circumference was measured with the subject standing, arms at the sides, feet together and abdomen relaxed, a horizontal measure is taken at the narrowest part of the torso (above the umbilicus and below the xiphoid process) at the level of the navel, using a flexible tape measure and extendable to one decimal place. Hip circumference was measured with the subject standing erect with the feet together, a horizontal measure is taken at the maximal circumference of the buttocks using a flexible tape measure and extendable to one decimal place. Waist to Hip ratio was calculated by dividing the waist circumference by the hip circumference.

Then patients filled information about their demographic and clinical profile in the self-structured questionnaire.

\section{Physical activity level measure}

Long form of IPAQ was administered to the patients to assess their PA level in the various domains. According to the guidelines for the data processing and analysis of IPAQ,${ }^{28}$ computations of the total scores requires summation of the duration (in minutes) and frequency (in days) for all the types of activities in all domains. Domain specific scores were computed by summation of the scores for walking, moderate-intensity and vigorous-intensity activities within each specific domain while the total scores in the different domains were calculated to yield an overall grand total. The metabolic equivalent (MET)-minute was computed by multiplying the MET score of an activity by the time in minutes. The PA level was expressed in MET-minutes/week. The PA level of the participants was categorized as moderate if the individual performs 3 or more days of vigorousintensity activity of at least 20 minutes per day OR 5 or more days of moderate-intensity activity and/or walking of at least 30 minutes per day OR 5 or more days of any combination of walking, moderateintensity or vigorous-intensity activities achieving a minimum total PA of at least 600 MET-minutes/week. It was categorized as high if an individual performs vigorous-intensity activity on at least 3 days achieving a minimum total PA of at least 1500 MET-minutes/week OR 7 or more days of any combination of walking, moderate-intensity or vigorous-intensity activities achieving a minimum total PA of at least 3000 MET-minutes/week. However, patients who did not meet the criteria for moderate or high PA level were considered to have a low PA level.

The environmental perception of the patients in relation to PA was assessed using the 39 item modified long form of ALPHA Environmental Questionnaire.

\section{Low back pain and disability measures}

Numerical rating scale was used to rate the patients pain intensity/ level. 0 indicates no pain, 1-3 indicates mild pain, 4-6 indicates moderate pain and 7-10 indicates severe pain.
RMDQ was administered to assess disability level of the patients. Scores on this questionnaire ranged from 0 (indicating no disability) to 24 (indicating severe disability). Patients responded by answering yes or no to indicate whether each statement represented a true description of their current disability owing to their condition. The number of items the participant ticked was summed and the score for the RMDQ was obtained.

Body Fat Percentage was determined by a body fat analyzer. The participants measured height was inputted and the sex selected in the machine. The participants were asked to stand bare footed on the platform of the machine with minimal clothing and percentage body fat was read, as calculated by the analyzer.

\section{Data analysis}

A descriptive statistics was used to summarize data in frequency and percentage tables. A step-wise multiple regressions were used to determine the predictors of the four domains of physical activity (jobrelated, transport, domestic/garden and leisure). Alpha level was set at $\mathrm{p}<0.05$. Statistical analysis was performed using Statistical Package for Social Sciences (SPSS, Chicago, IL, USA).

\section{Results}

The 57 participants involved in this study comprised of 25 males $(43.9 \%)$ and 32 females $(56.1 \%)$ with an age range of 21 to 69 years, mean age of $48 \pm 13.8$ years and mean BMI of $27.4 \pm 5.2 \mathrm{~kg} /$ $\mathrm{m} 2$. Table $1 \mathrm{~A}$ below shows the scio-demoraphic characteristics of the participants. Male participants had a higher JRPA (5940 METMinutes/week), TRPA (19152 MET-Minutes/week) and LTPA (4986 MET-Minutes/week) while female participant had a higher DGPA (10080 MET-Minutes/week) (Table 1B \& Table 2).

Table IA Socio-demographic characteristics of the participants

\begin{tabular}{|c|c|c|c|}
\hline \multirow{2}{*}{ Variables } & \multicolumn{3}{|c|}{ Number of participants (\%) } \\
\hline & Total & Male & Female \\
\hline \multicolumn{4}{|l|}{ Age (Years) } \\
\hline Less than 30 & $\mathrm{II}(19.3)$ & $9(36.0)$ & $2(6.2)$ \\
\hline 30 to 39 & $\mathrm{I}(\mathrm{I} .8)$ & $\mathrm{I}(4.0)$ & $0(0)$ \\
\hline 40 to 49 & $13(22.8)$ & $5(20.0)$ & $8(25.0)$ \\
\hline 50 to 59 & $19(33.3)$ & $5(20.0)$ & $14(43.8)$ \\
\hline 60 and above & $13(22.8)$ & $5(20.0)$ & $8(25.0)$ \\
\hline \multicolumn{4}{|c|}{ Marital status } \\
\hline Unmarried & $13(22.8)$ & II(44.0) & $2(6.3)$ \\
\hline Married & $35(61.4)$ & $12(48)$ & 23(71.8) \\
\hline Divorced & $2(3.5)$ & $0(0)$ & $2(6.3)$ \\
\hline Separated & $\mathrm{I}(\mathrm{I} .8)$ & $2(8)$ & $0(0)$ \\
\hline Widowed & $6(10.5)$ & $0(0)$ & $5(15.6)$ \\
\hline \multicolumn{4}{|c|}{ Years of working experience } \\
\hline Less than I & $18(31.6)$ & $9(36.0)$ & $9(28.1)$ \\
\hline I to 9 & $\mathrm{II}(19.3)$ & $5(20.0)$ & $6(18.8)$ \\
\hline 10 to 19 & $12(21.1)$ & $7(28.0)$ & $5(15.6)$ \\
\hline 20 to 29 & $6(10.5)$ & $\mathrm{I}(4.0)$ & $5(15.6)$ \\
\hline 30 and above & $10(17.5)$ & $3(12.0)$ & $7(21.9)$ \\
\hline
\end{tabular}


Table Continued...

\begin{tabular}{llll}
\hline \multirow{2}{*}{ Variables } & \multicolumn{3}{l}{ Number of participants (\%) } \\
\cline { 2 - 4 } & \multicolumn{1}{c}{ Total } & Male & Female \\
\hline Current employment status & & \\
Government Employed & $24(42.1)$ & $5(20.0)$ & $19(59.4)$ \\
Private Sector & $2(3.5)$ & $2(8.0)$ & $0(0)$ \\
Self Employed & $13(22.8)$ & $9(36.0)$ & $4(12.5)$ \\
Retired & $5(8.8)$ & $3(12.0)$ & $2(6.2)$ \\
Unemployed & $13(22.8)$ & $6(24.0)$ & $7(21.9)$ \\
Educational status & & & \\
No Formal Education & $5(8.8)$ & $0(0)$ & $5(15.6)$ \\
Primary Education & $7(12.3)$ & $1(4.0)$ & $6(18.8)$ \\
Secondary Education & $9(15.8)$ & $6(24.0)$ & $3(9.4)$ \\
Tertiary Education & $36(63.2)$ & $18(72.0)$ & $18(56.2)$ \\
Family or household size & & & \\
Less than 3 & $11(19.3)$ & $9(36.0)$ & $2(6.2)$ \\
3 to 5 & $20(35.1)$ & $6(24.0)$ & $14(43.8)$ \\
6 to 8 & $19(33.3)$ & $4(16.0)$ & $15(46.9)$ \\
9 to II & $6(10.5)$ & $5(20.0)$ & $1(3.1)$ \\
I2 and above & $1(1.8)$ & $1(4.0)$ & $0(0)$ \\
\hline
\end{tabular}

$\%$, percentage

Table I B cont'd: Socio-demographic characteristics of the participants

\begin{tabular}{llll}
\hline \multirow{2}{*}{ Variables } & \multicolumn{3}{c}{ Number of participants (\%) } \\
\cline { 2 - 4 } & Total & Male & Female \\
\hline Current family/residential arrangement & & \\
Living alone & $\mathrm{I} 5(26.3)$ & $13(52.0)$ & $2(6.2)$ \\
Living with spouse alone & $3(5.3)$ & $2(8.0)$ & $\mathrm{I}(3.1)$ \\
Living with spouse and children & $23(40.3)$ & $6(24.0)$ & $\mathrm{I}(53.1)$ \\
$\begin{array}{l}\text { Living with spouse and/or children } \\
\text { and other relations }\end{array}$ & $\mathrm{I} 6(28.1)$ & $4(16.0)$ & $\mathrm{I} 2(37.5)$
\end{tabular}

\section{Average monthly income (Naira)}

\begin{tabular}{llll} 
Less than I8,000 & $16(28.1)$ & $7(28.0)$ & $9(28.1)$ \\
I8,000 to less than 50,000 & $15(26.3)$ & $9(30.0)$ & $6(18.8)$ \\
50,000 to less than 150,000 & $16(28.1)$ & $3(12.0)$ & $13(40.6)$ \\
I 50,000 to less than 250,000 & $4(7.0)$ & $2(8.0)$ & $2(6.2)$ \\
250,000 and above & $6(10.5)$ & $4(16.0)$ & $2(6.2)$ \\
Tobacco smoking & & & \\
Current smoker & $1(1.8)$ & $0(0)$ & $1(3.1)$ \\
Former smoker & $6(10.5)$ & $6(24.0)$ & $0(0)$ \\
None smoker & $50(87.7)$ & $19(76.0)$ & $31(96.9)$ \\
Alcohol status & & & \\
Currently takes alcohol & $21(36.8)$ & $14(56.0)$ & $7(21.9)$ \\
Formerly takes alcohol & $4(7.0)$ & $2(8.0)$ & $2(6.2)$ \\
None at all & $32(56.1)$ & $9(36.0)$ & $23(7 \mid .9)$ \\
\hline
\end{tabular}

$\%$, percentage
Table 2 Clinical profile of the participants

\begin{tabular}{|c|c|c|c|}
\hline \multirow{2}{*}{ Variables } & \multicolumn{3}{|c|}{ Number of participants (\%) } \\
\hline & Total & Male & Female \\
\hline \multicolumn{4}{|c|}{ Duration of LBP (months) } \\
\hline Less than 12 & $12(21.1)$ & II (44.0) & $I(3.1)$ \\
\hline 12 to 36 & $18(31.6)$ & $9(36.0)$ & $9(28.1)$ \\
\hline 37 to 72 & $11(19.3)$ & $2(8.0)$ & $9(28.1)$ \\
\hline 73 to 108 & $7(12.3)$ & $\mathrm{I}(4.0)$ & $6(18.8)$ \\
\hline 109 and above & $9(15.8)$ & $2(8.0)$ & $7(21.9)$ \\
\hline \multicolumn{4}{|c|}{ No of physiotherapy treatment received per week } \\
\hline Once & $18(31.6)$ & $9(36.0)$ & $9(28.1)$ \\
\hline Twice & $3 I(54.4)$ & $14(56.0)$ & $17(53.1)$ \\
\hline Three times & $4(7.0)$ & $2(8.0)$ & $2(6.2)$ \\
\hline \multicolumn{4}{|l|}{ Four times } \\
\hline Five times & $4(7.0)$ & $0(0.0)$ & $4(\mid 2.5)$ \\
\hline \multicolumn{4}{|l|}{ Pain intensity } \\
\hline Mild pain & $9(15.8)$ & $5(20.0)$ & $4(12.5)$ \\
\hline Moderate pain & $28(48.1)$ & $14(56.0)$ & $14(43.8)$ \\
\hline Severe pain & $20(35.1)$ & $6(24.0)$ & $14(43.8)$ \\
\hline \multicolumn{4}{|l|}{ BMI (Kg/M2) } \\
\hline Underweight & $2(2.5)$ & $0(0)$ & $2(6.2)$ \\
\hline Normal & $17(29.8)$ & $10(40.0)$ & $7(21.9)$ \\
\hline Overweight & $20(35.1)$ & II (44.0) & $9(28.1)$ \\
\hline Obese & $18(31.6)$ & $4(16.0)$ & $14(43.8)$ \\
\hline
\end{tabular}

Key *Indicates significant at $\mathrm{p}<0.05$; BMI, body mass index; LBP, Low back pain; $X 2$, pearson chi square; \%, percentage

Majority of the participants reported their PA level to be of moderate and high intensity (Table 3).

Table 3 Categories of Physical Activity of the participants

\begin{tabular}{lll}
\hline Physical activity levels & Frequency & Percentage \\
\hline Low & 11 & 19.3 \\
Moderate & 18 & 31.6 \\
High & 28 & 49.1 \\
\hline
\end{tabular}

An analysis of the perceived environmental characteristics is presented in Table 4A \& Table 4B below.

Table 5 below shows the result the summary of stepwise multiple regression analysis to ascertain the significant predictors of Job-Related Physical Activity. Only four variables are significant predictors of Job-Related Physical Activity.

The significant predictors of transport-related physical activity are outlined in Table 6 below.

Table 7 below shows the results of the stepwise multiple regression analysis to determine the significant predictors of DGPA. The result shows that DGPA has the highest number of significant predictors. 
Table 4A Self-reported perceived environmental characteristics of the participants

\begin{tabular}{|c|c|c|c|}
\hline Variables & Total & Males $\mathrm{n}(\%)$ & Females n(\%) \\
\hline \multicolumn{4}{|l|}{ Detached House Residence } \\
\hline None/A few & $43(89.6)$ & $21(91.3)$ & $22(88.0)$ \\
\hline Some & $5(10.4)$ & $2(8.7)$ & $3(12.0)$ \\
\hline \multicolumn{4}{|l|}{ Semi-Detached House Residence } \\
\hline None/A few & $48(84.2)$ & $21(84.0)$ & $27(84.4)$ \\
\hline Some & $7(12.3)$ & $2(8.0)$ & $5(15.6)$ \\
\hline Most/All & $2(3.5)$ & $2(8.0)$ & $0(0)$ \\
\hline \multicolumn{4}{|c|}{ Apartment Buildings or Blocks of Flats Residence } \\
\hline None/A few & $15(26.3)$ & $6(24.0)$ & $9(28.1)$ \\
\hline Some & $\mathrm{I}(\mathrm{I} .8)$ & $0(0)$ & $I(3.1)$ \\
\hline Most/All & $4 I(7 I .9)$ & $19(76.0)$ & $22(68.8)$ \\
\hline \multicolumn{4}{|c|}{ Accessibility of Local shop(s) in the neighbourhood $\dagger$} \\
\hline 10 Minutes or less & $55(96.5)$ & 23(92.0) & $32(100.0)$ \\
\hline More than 10 minutes to 30 minutes & $\mathrm{I}(\mathrm{I} .80)$ & $\mathrm{I}(4.0)$ & $0(0)$ \\
\hline More than 30 minutes & $\mathrm{I}(\mathrm{I} .8)$ & $\mathrm{I}(4.0)$ & $0(0)$ \\
\hline \multicolumn{4}{|c|}{ Accessibility of Supermarket /public market in the neighbourhood $\dagger$} \\
\hline 10 minutes or less & $30(54.5)$ & $15(60.0)$ & $15(50.0)$ \\
\hline More than 10 minutes to 30 minutes & $\mathrm{II}(20.0)$ & $7(28.0)$ & $4(13.3)$ \\
\hline More than 30 minutes & |4(25.4) & $3(12.0)$ & II(36.7) \\
\hline \multicolumn{4}{|c|}{ Accessibility of Local services (bank, post office, or library) in the neighbourhood $\dagger$} \\
\hline 10 minutes or less & $55(96.5)$ & 23(92.0) & $32(100.0)$ \\
\hline More than 10 minutes to 30 minutes & $\mathrm{I}(\mathrm{I} .8)$ & $\mathrm{I}(4.0)$ & $0(0)$ \\
\hline More than 30 minutes & $\mathrm{I}(\mathrm{I} .8)$ & $\mathrm{I}(4.0)$ & $0(0)$ \\
\hline \multicolumn{4}{|c|}{ Accessibility of Restaurant in the neighbourhood $\dagger$} \\
\hline 10 minutes or less & $40(70.2)$ & $21(84.0)$ & $19(59.4)$ \\
\hline More than 10 minutes to 30 minutes & $10(17.5)$ & $3(12.0)$ & $7(21.9)$ \\
\hline More than 30 minutes & $7(12.3)$ & $\mathrm{I}(4.0)$ & $6(18.8)$ \\
\hline \multicolumn{4}{|c|}{ Accessibility of Bus Stop in the neighbourhood $\dagger$} \\
\hline 10 minutes or less & $4 I(7 I .9)$ & $21(84.0)$ & $20(62.5)$ \\
\hline More than 10 minutes to 30 minutes & $10(17.5)$ & $3(12.0)$ & $7(21.9)$ \\
\hline More than 30 minutes & $6(10.5)$ & $\mathrm{I}(4.0)$ & $5(15.6)$ \\
\hline \multicolumn{4}{|l|}{ Accessibility of Sport and leisure facility $\dagger$} \\
\hline 10 minutes or less & $\mathrm{II}(19.3)$ & $9(36.0)$ & $2(6.2)$ \\
\hline More than 10 minutes to 30 minutes & $5(8.8)$ & $\mathrm{I}(4.0)$ & $4(12.5)$ \\
\hline More than 30 minutes & $4 I(7 \mid .9)$ & $15(60.0)$ & $26(81.2)$ \\
\hline
\end{tabular}

Key† Time taken to trek from home to the nearest business/facilities in the neighbourhood 
Table 4B Cont'd: Self-Reported Perceived Environmental Characteristics of the participants.

\begin{tabular}{|c|c|c|c|}
\hline Variable & Total & $\begin{array}{l}\text { Male } \\
\text { n(\%) }\end{array}$ & $\begin{array}{l}\text { Female } \\
\mathbf{n}(\%)\end{array}$ \\
\hline \multicolumn{4}{|l|}{ Accessibility of Open Recreation area in the neighbourhood } \\
\hline & $21(36.8)$ & $13(52.0)$ & $8(25.0)$ \\
\hline 10 minutes or less & $8(\mid 4.0)$ & $2(8.0)$ & $6(18.8)$ \\
\hline More than 10 minutes to 30 minutes & $28(49.1)$ & $10(40.0)$ & $18(56.2)$ \\
\hline \multicolumn{4}{|l|}{ More than 30 minutes } \\
\hline Shopping at local stores & $18(31.6)$ & $5(20.0)$ & $13(40.6)$ \\
\hline Disagree & $39(68.4)$ & $20(80.0)$ & $19(59.4)$ \\
\hline \multicolumn{4}{|l|}{ Agree } \\
\hline Stores are within easy walking distance of Home & $3(5.3)$ & $3(12.0)$ & $0(0)$ \\
\hline Disagree & $54(94.7)$ & $22(88.0)$ & $32(100.0)$ \\
\hline \multicolumn{4}{|l|}{ Agree } \\
\hline Ease of walk to public transportation & $15(26.3)$ & $4(16.0)$ & II (34.4) \\
\hline Disagree & $42(73.7)$ & $2 I(84.0)$ & $2 I(65.6)$ \\
\hline \multicolumn{4}{|l|}{ Agree } \\
\hline Sidewalks availability & $37(64.9)$ & II (44.0) & $26(81.2)$ \\
\hline Disagree & $20(35.1)$ & $14(56.0)$ & $6(18.8)$ \\
\hline \multicolumn{4}{|l|}{ Agree } \\
\hline Neighbourhood pleasantness for walking & $12(2||)$. & $4(16.0)$ & $8(25.0)$ \\
\hline Disagree & $45(78.9)$ & $2 I(84.0)$ & $24(75.0)$ \\
\hline \multicolumn{4}{|l|}{ Agree } \\
\hline Neighbourhood neatness & $12(21.1)$ & $4(16.0)$ & $8(25.0)$ \\
\hline Disagree & $45(78.9)$ & $2 I(84.0)$ & $24(75.0)$ \\
\hline \multicolumn{4}{|l|}{ Agree } \\
\hline Presence of trees along the streets in the neighbourhood & $3 I(54.4)$ & $13(52.0)$ & $18(56.2)$ \\
\hline Disagree & $26(45.6)$ & $12(48.0)$ & 14(43.8) \\
\hline \multicolumn{4}{|l|}{ Agree } \\
\hline Presence of attractive natural sight in the neighbourhood & $50(87.7)$ & $22(88.0)$ & $28(87.5)$ \\
\hline Disagree & $7(12.3)$ & $3(12.0)$ & $4(12.5)$ \\
\hline \multicolumn{4}{|l|}{ Agree } \\
\hline Presence of attractive buildings/homes in neighbourhood & $16(28.1)$ & $3(12.0)$ & $13(40.6)$ \\
\hline Disagree & $4 I(7 I .9)$ & $22(88.0)$ & $19(59.4)$ \\
\hline \multicolumn{4}{|l|}{ Agree } \\
\hline Walking in the neighbourhood is dangerous due to traffic & $46(80.7)$ & $23(92.0)$ & $23(71.9)$ \\
\hline Disagree & II(I9.3) & $2(8.0)$ & $9(28.1)$ \\
\hline \multicolumn{4}{|l|}{ Agree } \\
\hline Walking in the neighbourhood is dangerous due to level of crime at day & $43(75.4)$ & $23(92.0)$ & $20(62.5)$ \\
\hline Disagree & $14(24.6)$ & $2(8.0)$ & $12(37.5)$ \\
\hline \multicolumn{4}{|l|}{ Agree } \\
\hline Walking in the neighbourhood is dangerous due to level of crime at night & $33(57.9)$ & $17(68.0)$ & $16(50.0)$ \\
\hline Disagree & $24(42.1)$ & $8(32.0)$ & $16(50.0)$ \\
\hline Agree & & & \\
\hline
\end{tabular}

Key $\dagger$ Time taken to trek from home to the nearest business/facilities in the neighbourhood

Citation: Ezeukwu AO, Ebisike GC, John DO, et al. Predictors of self-reported physical activity level in patients with non-specific chronic low back pain. Int Phys Med Rehab J. 2019;4(I):25-35. DOI: 10.15406/ipmrj.2019.04.00168 
Table 5 Predictors of job-related physical activity of the participants

\begin{tabular}{|c|c|c|c|c|c|c|}
\hline \multirow{2}{*}{ Predictors } & \multicolumn{2}{|c|}{ Un standardized coefficient } & \multicolumn{4}{|c|}{ Standardized coefficient } \\
\hline & B & Std. error & Beta & $\mathbf{R 2}$ & Adjusted R2 & P-value \\
\hline No of Physiotherapy Treatment received per week & 2493.094 & 524.412 & 0.528 & 0.247 & 0.23 & $0.000 *$ \\
\hline Age & -95.676 & 23.564 & -0.474 & 0.393 & 0.365 & $0.002 *$ \\
\hline Average Monthly Income & 600.409 & 292.07 & 0.242 & 0.458 & 0.419 & $0.03 I^{*}$ \\
\hline Shopping at Local Stores & -1383 & 682.823 & -0.227 & 0.507 & 0.459 & $0.049 *$ \\
\hline
\end{tabular}

*: Significant at $\mathrm{p}<0.05$

Table 6 Predictors of transport-related physical activity of the participants

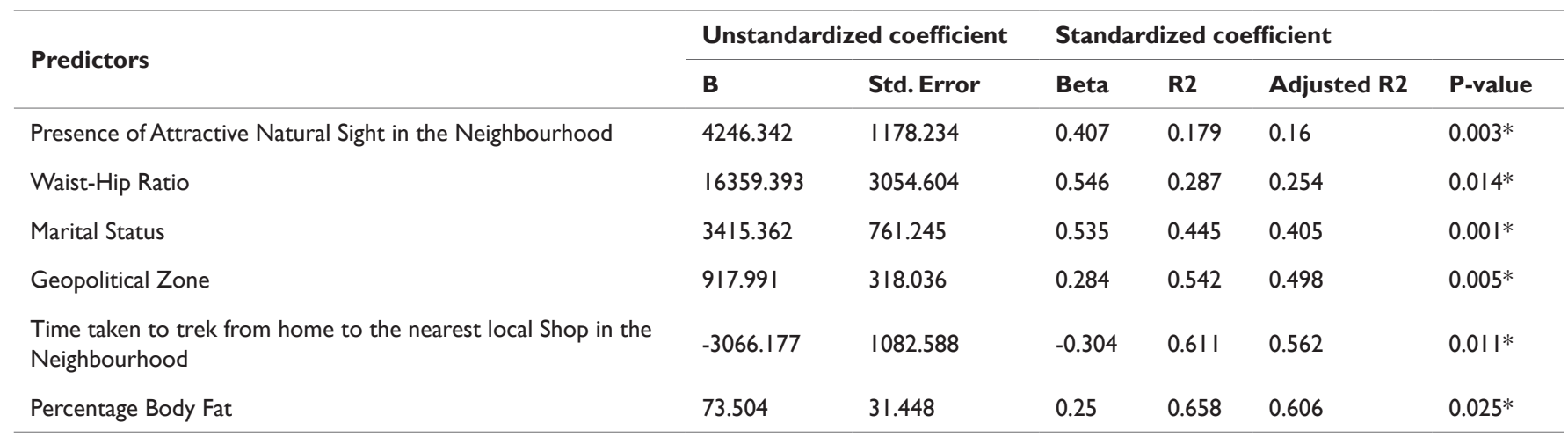

*: Significant at $\mathrm{p}<0.05$

Table 7 Predictors of domestic and garden (Yard work) Physical Activity (MET-Minutes/Week) of the participants

\begin{tabular}{|c|c|c|c|c|c|c|}
\hline \multirow{2}{*}{ Predictors } & \multicolumn{2}{|c|}{ Unstandardized coefficient } & \multicolumn{4}{|c|}{ Standardized coefficient } \\
\hline & B & Std. Error & Beta & $\mathbf{R 2}$ & Adjusted R2 & P-value \\
\hline Disability Index & $-285.37 \mid$ & 11.687 & -0.822 & 0.289 & 0.256 & $0.011^{*}$ \\
\hline Neighbourhood Neatness & -3287.651 & 178.986 & -0.664 & 0.442 & 0.402 & $0.002 *$ \\
\hline Time Taken to trek to the nearest Restaurant & 1432.482 & 105.035 & 0.522 & 0.59 & 0.55 & $0.000 *$ \\
\hline Family or Household Size & 787.799 & 65.157 & 0.399 & 0.689 & 0.65 & $0.00 I^{*}$ \\
\hline Ease of walk to Public Transportation Stop & 1655.447 & 242.971 & 0.307 & 0.745 & 0.713 & $0.002^{*}$ \\
\hline Pleasantness of Neighbourhood for Walking & 820.444 & $|76.76|$ & 0.171 & 0.8 & 0.769 & $0.002^{*}$ \\
\hline Tobacco Smoking Status & 2272.325 & $|75.4| \mid$ & 0.462 & 0.829 & 0.798 & $0.016^{*}$ \\
\hline Sidewalks Availability & -478.028 & 159.072 & -0.113 & 0.873 & 0.845 & $0.00 I^{*}$ \\
\hline $\begin{array}{l}\text { Walking in the Neighbourhood is dangerous due to Level of Crime } \\
\text { at Night }\end{array}$ & -518.415 & 149.756 & -0.127 & 0.903 & 0.878 & $0.002^{*}$ \\
\hline Intensity of pain & 365.898 & 43.507 & 0.32 & 0.924 & 0.902 & $0.003^{*}$ \\
\hline $\begin{array}{l}\text { Walking in the Neighbourhood is dangerous due to Level of Crime } \\
\text { at Day }\end{array}$ & -768.386 & 181.352 & $-0.16 \mid$ & 0.936 & 0.915 & $0.019 *$ \\
\hline Presence of Attractive Natural Sight in the Neighbourhood & -1096.063 & 246.321 & $-0.15 \mid$ & 0.945 & 0.924 & $0.027^{*}$ \\
\hline Proximity of Stores to Homes & -1682.903 & 346.643 & -0.204 & 0.951 & 0.932 & $0.042 *$ \\
\hline Highest Educational Level & -572.873 & 98.945 & -0.232 & 0.966 & 0.95 & $0.024^{*}$ \\
\hline Waist-Hip Ratio & 3458.822 & 689.917 & 0.166 & 0.976 & 0.962 & $0.003^{*}$ \\
\hline Walking is Quicker than Driving in the Neighbourhood & -487.059 & 163.282 & -0.118 & 0.979 & 0.966 & $0.042 *$ \\
\hline Apartment Buildings or Blocks of Flats Residence & 200.2 & 96.603 & 0.071 & 0.982 & 0.97 & $0.048 *$ \\
\hline
\end{tabular}

*: Significant at $\mathrm{p}<0.05$ 
Table 8 below shows the results of the stepwise multiple regression analysis to determine the significant predictors of LeisureTime Physical Activity (LTPA). The result shows that out of the 56 variables that were entered into the regression model, only 6 variables were significant predictors of LTPA.

Table 8 Predictors of leisure-time physical activity (MET-Minutes/Week) of the participants

\begin{tabular}{lllllll}
\hline \multirow{2}{*}{ Predictors } & \multicolumn{3}{l}{ Unstandardized coefficient } & \multicolumn{3}{l}{ Standardized coefficient } \\
\cline { 2 - 7 } & B & Std. Error & Beta & R2 & Adjusted R2 & P-value \\
\hline Sex & -721.194 & 180.086 & -0.419 & 0.264 & 0.247 & $0.000^{*}$ \\
Geopolitical Zone & 426.256 & 95.333 & 0.45 I & 0.34 I & 0.3 I & $0.030^{*}$ \\
Walking is Quicker than Driving in the Neighbourhood & 886.164 & 187.19 & 0.507 & 0.44 & 0.4 & $0.009 *$ \\
Highest Educational Level & 354.85 & 107.012 & 0.34 I & 0.519 & 0.472 & $0.013^{*}$ \\
Detached House Residence & 893.196 & 264.768 & 0.323 & 0.595 & 0.545 & $0.009 *$ \\
Neighbourhood Neatness & 562.431 & 207.068 & 0.27 & 0.66 & 0.607 & $0.010^{*}$ \\
\hline
\end{tabular}

*: Significant at $\mathrm{p}<0.05$

\section{Discussion}

\section{Socio-demographic and clinical characteristics of the participants}

The findings of this study revealed that there were more females than males among the participants. This may be due to the fact that more joints are affected in females than males although, it is known that males and females equally develop LBP. ${ }^{28}$ Most of the participants both were found to be in the age group of 50 to 59 years. This is in tandem with a study that reported about $55 \%$ of females and $45 \%$ of males to have low back pain and the highest age group with low back pain to be 55 to 64 years in a study on low back pain, lifestyle factor and physical activity. ${ }^{8}$ Hoy et al reported that low back pain is more common among people aged $40-80$ years, with the overall number of individuals affected expected to increase as the population ages..$^{29}$ Also greater number of the participants in the present study was found to be in the middle class. A small proportion of the participants reported to have an average monthly income less than the minimum wage while a lesser percentage was found to be among the rich class. Findings are consistent with that reported by Sheikh and Abdul in their study on clinical pattern of chronic low back pain. ${ }^{30}$ They found $75 \%$ of low back pains among subjects of middle class, $20 \%$ of the patients were poor and $5 \%$ of the subjects were rich. They opined that the rich may possibly have opted more for private clinics for treatments whereas the poor patients may not have had access and financial capacity to reach the multidisciplinary hospitals. Several studies also have shown that middle class individuals with chronic LBP attended more to hospitals..$^{28,31}$

Literature shows that the risk of low back pain is related more with childrearing although this effect might be partially mediated by some other confounders associated with increasing family size. ${ }^{32}$ Smoking also has been implicated in the incidence of low back pain, with both current and former smokers reported to have a higher prevalence and incidence of low back pain than never smokers..$^{33}$ The findings of this study however reported that over half of the participants reported to have a family size that is up to 5 members and majority being nonsmokers and non-alcoholics.

Furthermore, greater number of the female participants was found to be overweight or obese compared with the males. This may also have contributed to prolonged duration of LBP reported by the females. An increase in BMI may increase the intradiscal pressure in the vertebral disc of the lumbar vertebrae particularly the L4 and L5 intervertebral disc into prolapse and herniation. For patients that have low back pain, large BMI may retard the rate of healing because of the weight bearing on the compromising structure. ${ }^{34}$

In addition, more than half of the participants reported moderate/ sever pain intensity, but over eighty percent of the participants received at most two sessions of physiotherapy treatment every week. This could be as result of low economic status of the patients leading to inability to afford frequent visit to the clinic or may be due to the location or distance of the clinic from the patients' homes.

\section{Physical activity level of the participants}

Majority of participants attained the level of at least 30 minutes of moderate physical activity 5 days a week, which could be considered as the lowest level of physical activity for achieving health benefits. ${ }^{35}$ This implies that most of the patients had a physical activity level that was within moderate and high. The high level of PA indicated in this study may be explained by the Avoidance-Endurance Model (AEM), which emphasizes that individuals with NSCLBP ignore their pain and persist on moving around despite their pain. ${ }^{36}$ This is in contrast to the assumptions of the fear avoidance belief as shown by some studies, which expects people with chronic pain to reduce their participation in physical activity due to fear of pain that may accompany reoccurrence or fear of exacerbation of pain. ${ }^{37,38}$ Conversely, two other systematic reviews indicated that individuals with chronic low back pain engaged in similar levels of physical activity compared with asymptomatic controls. ${ }^{36,39}$ However, all these studies involved an objective assessment of physical activity and a reduced sample size, which could account for the variation between their results and that of this present study. Thus a prospective study employing larger sample size and objective assessment of PA level should be carried out among individuals with NSCLBP. However, in most studies recommended levels of PA have been determined in relation to leisure-time PA, while other domains (job-related, transportation, domestic and garden) were not equally considered. ${ }^{40}$ Therefore, studies using new integrated approach of determining PA level throughout four domains, as is IPAQ, could find considerably lower levels of physical inactivity. ${ }^{41}$

Also, the result of the present study showed that the male participants recorded a higher PA level than the females. This may be due to the fact that most of the males were physically active in their 
leisure-time while the females showed inactivity in their leisure-time. A similar study that assessed the PA level of patients with NSCLBP and its association with demographic variables reported that greater number of patients $(61.5 \%)$ was on moderate PA level and more male were involved in higher PA than female participants. Thus they opined that larger percentage of NSCLBP patients in their environment were within low and moderate PA level..$^{42}$ Likewise, a study done among healthy subjects have shown that females have lower PA as compared to males. ${ }^{41}$ The males in this present study were more physically active at their job and leisure-time and were more active commuters than their female counterparts. The female participants were noted to have greater domestic PA.

\section{Perceived environmental characteristics of the participants}

Self-reported access to sports and leisure facilities, location of stores within easy walking distance of home, availability of sidewalks, and perception of attractive buildings/homes in the neighbourhood were contingent on sex. This may explain while male participants recorded a higher level of leisure time PA whereas the females recorded a higher leisure-time physical inactivity. Meanwhile, 'location of stores within easy walking distance of home" was contingent on being a female. This is expected since the females are mostly the ones saddled with the task of home keeping, child care and shopping thus they should be disposed to better perception of the location of stores within their neighbourhood. All the female respondents were found to perceive stores to be located within easy walking distance of home and may have contributed to the increased domestic and garden PA among the females reported in this study.

\section{Predictors of the domains of physical activity of the participants}

The findings of the study showed that 'twice number of physiotherapy treatment received per week, age group of $30-39$ years, average monthly income of less than 18,000 naira and selfreported shopping at local stores accounted for $23 \%, 13.5 \%, 5.4 \%$ and $4 \%$ respectively of the variance due to Job-Related Physical Activity (JRPA). Together these variables accounted for $45.9 \%$ of the variance due to JRPA. Thus $54.1 \%$ of JRPA score could not be accounted for in this study.

Similarly, perception of attractive natural sight in the neighborhood, waist-hip ratio, being married, geopolitical zone (south East), perceived local shop located more than $10-30$ minutes from the home and percentage body fat accounted for $16 \%, 9.4 \%, 15.1 \%, 9.3 \%, 6.4 \%$, and $4.4 \%$ of the variance due to Transport-Related Physical Activity (TRPA). These variables altogether were only able to predict $60.6 \%$ of the variance in TRPA. This implies that $39.4 \%$ of the variance due to TRPA was not accounted for in this study. Therefore, there are other factors that contribute to the percentage of variance in TRPA.

Furthermore, the predictors of Domestic and Garden Physical Activity (DGPA) were found to include the socio-demographic variables-'family/household size of 3-5 members (10\%), nil tobacco smoking $(2.9 \%)$ ', clinical variables-'moderate pain at the low back $(2.4 \%)$, increased waist-hip ratio $(1.2 \%)$, decreased disability index (25.6\%)', and perceived environmental variables-'poor neighborhood neatness $(14.6 \%), 10$ minutes or less taken to trek to the nearest restaurant (14.8\%), Ease of walk to public transportation stop $(6.3 \%)$, pleasantness of neighborhood for walking (5.6\%), Sidewalks availability $(4.7 \%)$, crime safety at night $(3.3 \%)$, crime safety at day $(1.3 \%)$, presence of attractive natural sight in the neighborhood
$(0.9 \%)$, proximity of stores to homes $(0.8 \%)$, perception of walking being quicker than driving in the neighborhood $(0.4 \%)$, more apartment buildings or blocks of flats residence in the neighborhood $(0.4 \%)$ '. In summation, socio-demographic variables accounted for $12.9 \%$ of variance in DGPA, clinical variables accounted for $29.2 \%$ of the variance in DGPA while perceived environmental variables accounted for $53.1 \%$ of variance in DGPA. Together these variables accounted for $97 \%$ of the variance due to DGPA which is almost a complete prediction for DGPA. However there are other factors that contribute to the percentage of variance in DGPA as about 3\% of DGPA score could not be accounted for in this study.

Besides, the findings of the present study imply that sex (male), geopolitical zone (South East), perception of walking being quicker than driving in the neighborhood, higher educational status, perceived none/a few detached house residence in the neighborhood and good neighborhood neatness accounted for $24.7 \%, 6.3 \%, 9 \%, 7.2 \%, 7.3 \%$ and $6.2 \%$ of the variance due to Leisure-Time Physical Activity (LTPA) respectively. Together these variables accounted for $60.7 \%$ of the variance due to LTPA. This implies that about $39.3 \%$ of LTPA score could not be accounted for in this study.

\section{Conclusion}

There was higher incidence $(56.1 \%)$ and longer duration of NSCLBP among the females participants. The socio-demographic, clinical and environmental variables assessed in the study were only able to account for $45.9 \%, 60.6 \%, 97 \%$ and $60.7 \%$ of the variance in JRPA, TRPA, DGPA and LTPA domains respectively. Thus more parameters, like enjoyment in activities, knowledge of exercise health benefits, barriers to physical activity and social support etc., should be included in future studies in order to comprehensively determine the correlates of the domains of physical activity.

\section{Implication of the study for practice}

Since some modifiable variables are among the predictors of TRPA [waist-hip ratio (9.4\%), percentage body fat (4.4\%)] and DGPA [waist-hip ratio $(1.2 \%)$, intensity of pain $(2.4 \%)$, disability index $(25.6 \%)]$, health professionals should give correct advice on how the patients can reduce their general body weight/fat especially weight in the waist region in order to enhance their participation in PA at home and leisure time.

Finally several environmental characteristics assessed in this study were among the predictors of JRPA (4\%), TRPA (16\%), LTPA $(22.5 \%)$ and DGPA $(53.1 \%)$. Thus, these environmental characteristics should be incorporated in the formulation and implementation of health and physical activity promotion programs for these patients and also considered when prescribing home programs for these patients.

\section{Funding details}

There was no funding for this study

\section{Acknowledgments}

$$
\text { None }
$$

\section{Conflicts of interest}

The authors declare that there is no conflicts of interest.

\section{References}

1. Balagué FI, Mannion AF, Pellisé F, et al. Non-specific low back pain. Lancet. 2012;1379(9814):482-491. 
2. Burton AK, Tillotson KM, Main CJ, et al. Psychosocial predictors of outcome in acute and sub chronic low back trouble. Spine. 1995;20(6):722-728.

3. Waddell G. Back pain revolution. 2nd edn. BMJ Publishing Group: Edinburgh; 2004.

4. Airaksinen O, Brox JI, Cedraschi C, et al. European guidelines for the management of chronic nonspecific low back pain. Eur Spine J. 2006;15(Suppl 2):s192-s300.

5. Björck-van Dijken C, Fjellman WA, et al. Low back pain, lifestyle factors and physical activity: a population based-study. J Rehabil Med. 2008;40(10):864-869.

6. Oliveira R, Cabri J. Low back pain in young people - cross-sectional study in Lisbon. Paper presented at the AIESEP. 2005 World Congress, Lisbon; 2006.

7. Horng YS, Hwang YH, Wu HC, et al. Predicting health-related quality of life in patients with low back pain. Spine. 2005;30:55-65

8. Dijken BC, Fjellman WA, Hildingsson C. Low back pain, lifestyle factors and physical activity: A population-based study. J Rehab Med. 2008;40(10):864-869.

9. Office of Disease Prevention and Health Promotion. Physical Activity Guidelines for Americans. USA:ODPHP Publication No.U0036; 2008 October.

10. Bentsen SB, Hanestad BR, Rustoen T, et al. Quality of life in chronic low back pain patients treated with instrumented fusion. J Clin Nurs. 2008;17(15):2061-2069.

11. Smuck M, Kao MC, Bar N, et al. Does physical activity influence the relationship between low back pain and obesity?. Spine J. 2014;14(2):209-216.

12. Koes BW, vanTulder MW, Lin CC, et al. An updated overview of clinical guidelines for the management of non-specific low back pain in primary care. Eur Spine J. 2010;19(12):2075-2094.

13. Bussmann HB, Reuvekamp PJ, Veltink PH, et al. Validity and reliability of measurement obtained with an "activity monitor" in people with or without a transtibial amputation. Phys Ther. 1998;78(9):989998.

14. Verbunt JA, Westerterp KR, Van Der Heijden GJ, et al. Physical activity in daily life in patients with chronic low back pain. Arch Phys Med Rehabil. 2001;82(6):726-730.

15. Elfving B, Andersson T, Grooten WJ. Low levels of physical activity in back pain patients are associated with high levels of fear-avoidance beliefs and pain catastrophizing. Phys Res Int. 2007;12(1):14-24.

16. Thomas E, Silman AJ, Croft PR, et al . Predicting who develops chronic low back pain in primary care: a prospective study. $B M J$ 1999;318(7199):1662-1667.

17. Henschke N, Maher CG, Refshauge KM, et al. Prognosis in patients with recent onset low back pain in Australian primary care inception cohort study. BMJ. 2008;337:a171.

18. Enthoven P, Skargren E, Carstensen J , et al. Predictive factors for 1-year and 5-year outcome for disability in a working population of patients with low back pain treated in primary care. Pain. 2006;122:137-144.

19. Pincus T, Burton AK, Vogel S, et al. A systematic review of psychological factors as predictors of chronicity/disability in prospective cohorts of low back pain. Spine. 2002;27:E109-E120.

20. Pincus T, Vlaeyen JW, Kendall NA, et al. Cognitive-behavioral therapy and psychosocial factors in low back pain: directions for the future Spine. 2002;27:E133-E138.

21. World health organization. International classification function disability and health. 2001
22. Brouwer S, Kuijer W, Dijkstra PU. Reliability and stability of the roland morris disability questionnaire: intra class correlation and limits of agreement. Disabil Rehabil. 2004;26(3):162-165.

23. Spittaels H, Verloigne M, Gidlow C, et al. Measuring physical activityrelated environmental factors: reliability and predictive validity of the European environmental questionnaire. ALPHA. Int J Behav Nutr Phys Act. 2010;7(1):48.

24. Buchholz AC, Bartok C, Schoeller DA. The validity of bioelectrical impedance models 2004;19(5):433-446.

25. Roland MO, Morris RW. A study of the natural history of back pain. Part I: Development of a reliable and sensitive measure of disability in low back pain. Spine. 1983;8:141-144.

26. Craig CL, Marshall AJ, Sjostrom M, et al. International Physical activity questionnaire. 12-country reliability and validity. Med Sci Sports Exer 2003;35(8):1381-1395.

27. Guidelines for Data Processing and Analysis of the International Physical Activity Questionnaire (IPAQ) - Short and Long Forms November 2005.

28. Shakoor MA, Hug MN, Khan AA, et al. Effects of ultrasound therapy (UST) in osteoarthritis of the knee joint. CM-O-S (child) Health J. 2003;1(2):11-16.

29. Hoy D, Bain C, Williams G. A systematic review of the global prevalence of low back pain. Arth Rheumatol. 2012;64(6):2028-2037.

30. Sheikh JA, Abdul HR. Clinical pattern of chronic low back ache: A prospective study of 210 cases at a multidisciplinary hospital. $J K-$ Pract. 2014;19(1-2):21-27.

31. Solomon L. Clinical features of osteoarthritis. In: Ruddy S, Harris ED, et al, editors. Kelly's textbook of rheumatology. Philadelphia: Sanders WB. 2001:1409-1418.

32. Silman AJ, Ferry S, Papageorgiou AC, et al. Number of children as a risk factor for low back pain in men and women. Arthr Rheum. 1995;38(9):1232-1235.

33. Shiri R, Karppinen J, Leino AP, et al. The association between smoking and low back pain: a meta-analysis. Am J Med. 2010;123(1):87.e7-35.

34. Ojoawo A, Olaogun AM, Bamiwoyec BS. Relationship between Pain Intensity and Anthropometric Indices in women with low back pain - A Cross - Sectional Study. J Phys Ther. 2011;3(2):45-51.

35. Haskell WL, Lee IM, Pate RR, et al. Physical activity and public health: updated recommendation for adults' from the American college of sports medicine and the american heart association. Med Sci Sports Exerc. 2007;116:1081-1093.

36. Rudy T, Weiner D, Lieber S, et al. The impact of chronic low back pain on older adults: a comparative study of patients and controls. Pain. 2007;131(3):293-301.

37. Duque I, Para J, Duvallet A. Aerobic fitness and limiting factors of maximal performance in chronic low back pain patients. $J$ Back Musculoskelet Rehabil. 2009;22(2):113-119.

38. VanWeering M, Vollenbroek HM, Roessingh KM, et al. Daily physical activities of patients with chronic pain or fatigue versus asymptomatic controls. A systematic review. Clin Rehabil. 2007;21(11):1007-1023.

39. Griffin DW, Harmon DC, Kennedy NM. Do patients with low back pain have an altered level and/or pattern of physical activity compared to healthy individuals? A systematic review of the literature. Physiother. 2012;98:13e23.

40. Rutten A, Ziemainz H, Schena F, et al. Using different physical activity measurements in eight european countries. results of the european physical activity surveillance system (EUPASS) time series survey. Pub Health Nutr. 2003;6:371-376. 
41. Jurakia D, Pedišia Z, Andrijaševia M. Physical activity of croatian population: cross- sectional study using international physical activity questionnaire. Croat Med J. 2009;50:165-173.
42. Ojoawo AO, Awoniyi O. Association between physical activity level and demographic variables in patients with non-specific chronic low back pain. Afr J Phys Health Edu Dance. 2012;18(3):1117-4315. 